\title{
СУДЕБНЫЙ КОНТРОЛЬ КАК МЕХАНИЗМ АДМИНИСТРАТИВНОГО КОНТРОЛЯ В СТРАНАХ ОБЩЕГО ПРАВА
}

Аннотация. В научной статье судебный контроль подвергается анализу как общий процесс административного контроля путем рассмотрения его в общем праве. Будет четко определена роль судебного пересмотра (контроля) и срера рассмотрения альтернативных механизмов урегулирования споров. Цель состоит в том, чтобы проанализировать суть судебного пересмотра (контроля) и уточнить особенности его функционирования. Благодаря этому можно определить соответствующее конституционное и институциональное положение судов и судебного пересмотра (контроля) в пределах системы административного правосудия. Методологическую основу научной статьи составили общенаучные методы познания, в том числе: метод системного анализа, метод комплексного подхода, сравнительно-правовой, формально-логический, системно-структурный, формально-юридический, юридико-технический методы исследования. Основное предположение, высказанное в этой статье, заключается в том, что судебный пересмотр (контроль) используется не в тех целях, для которых он был разработан. Он не смог проявить себя должным образом в качестве основного направления административного правосудия. Критические замечания относительно судебного пересмотра (контроля), в основном, сводятся к тому, что на него полагаются в плане выполнения гораздо большего спектра задач, которые выдвигаются в рамках функционирования интегрированной системы административного права.

Ключевые слова: судебный контроль, административные трибуналы, пересмотр по существу, законность, принцип превышения власти, теория надзора, надзор, апелляция, обоснование решений, окончательность решений.

Review. The scientific article seeks to analyze judicial review as a general administrative control process by looking generally at its common-law origins. The author defines the role of judicial review and the space for consideration of alternative ways of disputes settlement. The aim is to analyze the nature of judicial review and the peculiarities of its functioning. Through this, an appropriate place for the courts and judicial review can be determined, both constitutionally and institutionally, within an inclusive system of administrative justice. General scientific methods of cognition such as the methods of analysis, comparative methods, systems and structural methods, legal and technical research methods form the methodological basis of the article.An underlying assumption of this article is that judicial review is being used in a manner for which it was not designed. As a primary avenue of administrative justice, it fails to accord the level of justice that it should. The criticisms which relate to judicial review do so largely because it is being relied on to perform all the tasks which should be allocated to a larger and more integrated system of administrative law.

Keywords: watchdog theory, Ultra Vires Doctrine, legality, merits review, administrative tribunals, judicial review, supervision, appeal, reasons, finality.

П о причине того, что судебный пересмотр (контроль) был основан и изначально действовал в Англии, он был заимствован в большинстве других стран общего права и исторически был самым важным инструментом контроля органов исполнительной власти.
Прежде, чем подробно рассмотреть роль судов в оценке административных действий, должно быть установлено, почему и как суды получили такие полномочия. В модели разделения полномочий у каждой власти есть их собственная конституционная и установленная функция. Однако 
происходит так, что эти строгие границы нарушаются. Примером этого служит то, что суды берут на себя рассмотрение действий административных подразделений. Власть любой общественной организации подчиняется закону, они все имеют законные ограничения, не существует понятия абсолютной или неограниченной исполнительной власти. Поэтому главная цель административного права удерживать правительственные органы в рамках закона для защиты граждан от превышения полномочий.

Государственные органы не могут действовать, как им нравится. Их действия должны быть законными, и они могут осуществлять только полномочия, данные им Парламентом напрямую (такая система основана на теории парламентского суверенитета, существующего в Англии) или в соответствии с Конституцией. Основанием для судебного пересмотра (контроля) является то, что у судов есть власть оценивать действия исполнительных органов, которые находятся вне сферы их компетенции. Причина этого состоит в том, что вся общественная власть подвергается определенной форме судебного контроля. Судебный пересмотр (контроль) представляет собой процесс, в рамках которого суд может выявлять, исправлять нарушения и несоответствия закону в действиях исполнительной власти. По словам Буля ясное определение роли судебного контроля было представлено на Совете в Йоханнесбурге (Consolidated Investment Co v Johannesburg Town Council), где главный судья заявил, что каждый раз, когда государственный орган, имея установленные обязанности, игнорирует важные положения устава или допускает грубые нарушения или очевидное несоответствие закону при исполнении обязанностей, то суд может пересмотреть дело, по которому поступила апелляция, и отменить или исправить принятое ранее решение. Для этого не требуется специальный правовой механизм, суды изначально обладают такими полномочиями [1].

К недавним заявлениям о роли судебного пересмотра (контроля) относится утверждение (Fedsure Life Assurance Ltd v Greater Johannesburg Transitional Metropolitan Council) о том, что главная концепция конституционного порядка заключается в том, что законодательные и исполнительные органы в каждой сфере ограничены принципом, что они могут осуществить власть или выполнять только те функции, которые предписаны им законом [2].

Некоторые источники [3] объясняют, что хотя исторически судебный пересмотр (контроль) сло- жился в рамках общего права, его длительное существование и актуальность уходят корнями в Конституцию. Судебный пересмотр (контроль) служил цели наделять суды полномочиями, признавая превосходство Парламента, устанавливать ограничения на осуществление исполнительной власти. Такая власть была закреплена за английскими судами как часть их юрисдикции в общем праве.

И хотя общее право по-прежнему имеет отношение к этому процессу, судебный пересмотр (контроль) решений, принятых органами государственной власти, - это конституционный вопрос, который осуществляется в соответствии с конституцией и ее условиями. Кроме того, сохраняя первенство с точки зрения общего права, судебный надзор был также внесен в законодательство в отдельных странах Содружества. Например, законодательно предусматривается кодификация оснований для пересмотра, описанная в Законе об административном праве (Судебных пересмотрах) Австралии (Administrative Decisions (Judicial Review) Act) от 1977 г.

Когда суды рассматривают административные действие, они обычно действуют, опираясь на имеющееся основание для повторного рассмотрения. Это основание позволяет суду решить, было ли незаконное действие или нарушение в принятии мер, и затем принять соответствующее решение. Однако, основание - это только часть более общего понятия, которое лежит в основе объяснения функций судебного пересмотра, а именно, законности (legality). Следует согласиться с Булем, который утверждает, что понятие законности является источником большинства оснований для повторного судебного рассмотрения [4]. В основе полномочия, благодаря которому судебная власть может контролировать действия исполнительной власти, исторически заложен принцип превышения власти (Ultra Vires Doctrine). Это означает, что исполнительная власть может действовать только законно и руководствоваться предписанными ей полномочиями.

Принцип превышения власти тесно связан с понятием разделения полномочий и парламентского суверенитета. Он подразумевает, что парламент наделяет государственные органы определенными полномочиями или властью, в рамках которых они и должны действовать. Функция суда заключается в применении законов, установленных парламентом, и гарантии того, что государственные органы действуют в пределах их полномочий. Судебный пересмотр (контроль) имеет 
законные основания, поскольку выполняет волю парламента, что соответствует идее парламентского суверенитета.

Существуют два варианта понимания принципа превышения власти, узкое и широкое. Разница заключается лишь в том, что узкое понимание предполагает соответствие принципу законности, в то время как в широком понимании требуется соблюдение принципа верховенства права. В английском прецедентном праве доминирует широкое понимание этого принципа. Милн утверждает, что при рассмотрении вопроса об отмене работы любого административного трибунала с точки зрения незаконности или наличия нарушений, всегда возникает вопрос, в действиях трибунала присутствует превышения власти или нет [5].

Согласно Хойкстеру, хотя и аппеляционная жалоба и повторное судебное рассмотрение является средством пересмотра решения, принятого органом исполнительной власти или трибуналом более низкого уровня, они осуществляют пересмотры разными способами и, соответственно, преследуют разные цели [6]. Апелляция занимается рассмотрением по существу дела (конкретным обстоятельствам дела) и устанавливает, было ли принятое решение верным. Поэтому судьи апелляции могут объявить решение правильным или неправильным. С другой стороны, повторное рассмотрение в суде не касается существа дела. Когда суды рассматривают решения, они оценивают способ, которым оно было достигнуто, чтобы определить, был ли этот способ законным. В сущности, это означает, что суд определяет законность действий, или было ли решение достигнуто в соответствии с определенной процедурой и законным способом. Соображения, которые учитываются, связанные с процессом, и не выявляют относящиеся к делу обстоятельства, которые способны оправдать результат.

Обоснованность действий судов и судей, в особенности проявляющих юридическую сдержанность и почтительное отношение к органам исполнительной власти, состоит в том, что пересмотр по существу дела и вывод о том, что первоначально принятое решение было неверным, подразумевает неконституционную узурпацию конституционной функции исполнительной власти. Если суды рассматривают только метод и процедуру, они не подвергают сомнению изначальное право органов исполнительной власти принимать самостоятельные решения, а скорее выполняют их собственную конституционно определенную функцию. Хойкстер объясняет, что различие отражает разделение полномочий, фундаментальную основу конституционного порядка. Она полагает, что из английского законодательства была унаследована «теория надзора» (watchdog theory), которая определяет суды как инстанции для проверки деятельности исполнительной власти [6].

Однако такое категоричное различие между апелляцией и судебным пересмотром не так очевидно на практике, как это может выглядеть в теории. Хойкстер подтверждает, что на самом деле в некоторых случаях невозможно отделить вопрос по существу от остальной части рассмотрения дела, так как суд не может эффективно оценить законность решения, не рассматривая, в том числе вопросов по существу [6]. Одним из наиболее спорных моментов является проверка обоснованности, но это не единственный пример. Хойкстер перечисляет несколько других оснований для пересмотра и объясняет, как расследование того, были ли основания, неизбежно включает рассмотрение вопросов по существу дела. Сюда относится: было ли проведено соответствующие рассмотрение, или преследовалась скрытая цель лицом, принимающим решение, или было продиктовано решение неуполномоченным лицом или органом, придерживалось ли лицо, принимающее решение, строгих принципов и правил судебного прецедента.

Однако важность различия все еще относительна при возникновении вопроса о функции судебного пересмотра. Вследствие того, что пересмотр касается процедуры принятия решения, суды могут ограничиться определением соблюдения законности и не ставить себя в двусмысленное положение между судебным вмешательством и судебной сдержанностью. Этот принцип позволил бы не выходить за рамки судебного пересмотра и не провоцировать неконституционную узурпацию функциональной компетентности со стороны судебной власти. В то же время очень часто может возникать потребность пересмотра по существу дела, особенно в области административного права. Поэтому судебный пересмотр не должен служить первоочередным органом для вмешательства. Скорее если достигнутое решение является неверным и требует не пересмотра процедуры, а исправления ошибочного решения, то необходима система апелляций, куда можно было бы обращаться с заявлениями.

Хойкстер заявляет, что судебный пересмотр характеризуется непрерывной напряженностью между двумя противостоящими идеалами: идеалом свободы действий органов исполнительной 
власти и идеалом судебного контроля [6]. Причина напряженности это, в конечном счете, политический вопрос. Суды пытаются не переступить через отведенную им роль и не посягать на сферу деятельности исполнительной или законодательной власти. Причина в том, что деятельность административных органов и официальных лиц, рамки которой определены законодательными органами, выбранными демократическим способом для выполнения определенных функций (включая рассмотрение вопросов права, фактов и образа действий), противостоят судебной власти (конституционной, общего права или приобретенной законным порядком) с функцией осуществления контроля, рассмотрения проблем или корректировки действий.

Суды попытались снизить потенциально недемократические последствия решений, сводя свою работу до механистической роли, сосредоточившись на строгих классификациях функций, чтобы ограничить их влияние. Однако в конституционном государстве, где у судебной власти есть ответственная, влиятельная роль достижения социально-экономических прав, такой формализм и концептуализм не совпадает с их целью. Следует согласиться с Милном, что отказ от строгой классификации функций как существенного критерия не только соответствует современным тенденциям административного права, но и способствует более рациональному применению правил естественного правосудия в этой сфере [7].

Судебный надзор - это важная и существенная гарантия против незаконного присвоения государственной власти. Однако важно иметь в виду, что суды не могут и не должны быть единственным средством защиты прав. Только интегрированная система ответственных исполнителей административного права, которые работают слаженно с гибким подходом к постановке задач, приведет к положительным социальным изменениям. По словам Боуля, политические институты не рассматриваются как подходящие для самостоятельного контроля над государственной властью и, что должны быть развиты новые административные принципы, процедуры и закон, обеспечивающий демократический и политический контроль над теми, кто осуществляет государственную власть [4]. Идея состоит в том, чтобы создать баланс между внутренним и внешним, судебным и политическим административным контролем. Такой подход к контролю административных действий допускает ограниченную роль судебного пересмотра и суда как механизма управления и улучшения уровня последовательных административных принципов и процедур.

По словам Вульфа роль судебного пересмотра (контроля) как важного гаранта государственной власти, ни в коем случае не должна уменьшаться. Вульф и Хойкстер предполагают, что существует опасность снижения уровня судебного пересмотра до второстепенной роли, во-первых, потому что есть доказательства, что количество дел в судебном пересмотре растет с каждым годом и, во-вторых, потому что существует повышенная информированность чиновников исполнительной власти о возможных последствий судебного рассмотрения $[8,6]$. Эффективность, практическая ценность и уместность судебных решений будет достигнута, только когда судьи станут проявлять понимание к сложным и загруженным политикой решениям административных чиновников. Отказ сотрудничать в таком случае может привести к большей степени формализма и распространению бюрократизации.

В то время как судебный пересмотр может быть окончательной и самой высокой формой контроля, он не может существовать отдельно и должен рассматриваться в более широком контексте всех форм контроля и средств управления, доступных в административном праве. Судебный пересмотр просто не может выполнить все функции управления, необходимые в сложной, многоуровневой системе административного права. По словам Вульфа судебный пересмотр обеспечивает только одно из многих юридических средств контроля за административными действиями, и его роль неизбежно нерегулярная и вспомогательная. Административный процесс не является и не может быть относится к спорам, подлежащих рассмотрению в суде [8].

Это означает, что судебный пересмотр должен сохранить свою авторитетную роль окончательной защиты против злоупотреблений в административной системе и защитника законных прав граждан. В то же время должна быть интегрированная система проверок и средств управления на более низком, административном уровне, чтобы обеспечить эффективное, качественное и последовательное осуществление административных прав. Как утверждает Хойкстер государственная власть существует для управления и, если находятся серьезные основания для пересмотра независимым судебным органом предпринятых ею действий или вынесенных решений, то административная деятельность будет затормаживаться [6]. 
Можно суммировать некоторые основные и выделить типы критических замечаний в отношении судебного пересмотра. Прежде всего, пересмотр рассматривается как второстепенный или вспомогательный в трех различных смыслах. Опираясь на взгляды Фуллера, можно утверждать, что, во-первых, судебный пересмотр не занимается вопросами, которые не являются предметом рассмотрения в судебном порядке[9]. Во-вторых, соглашаясь с Хойкстер, Харлоу, и Хатчинсон, можно утверждать, что нет никакого неопровержимого доказательства, что результаты негативных выводов судебного пересмотра заставят чиновников с административными функциями обязательно изменить свои методы принятия решений. Фактически, могут даже быть негативные последствия, и административные служащие могут использовать оборонительную практику, которая ограничит их ответственность, а не сосредотачиваться на том, чтобы сделать процесс принятия решений лучше. [10]. В-третьих, пересмотр не обязательно предоставляет истцам желательный результат. Истцы обычно ожидают благоприятного для них независимого решения, а не просто рассмотрения изначального решения в соответствии с процедурными требованиями. Критика в большей степени связана с установленной целью судебного пересмотра, который не должен заниматься изысканиями по существу дела, а проверяет соответствие формы и процедуры.

Соглашаясь с взглядами Вульфа и Кейна второй критический аргумент состоит в том, что пересмотр носит отрицательный и относящийся к прошлому характер. Это означает, что вместо того, чтобы прогрессивно нацелиться на обеспечение лучших результатов в принятии административных решений в будущем, судебный пересмотр уделяет внимание только тем случаям ненадлежащего управления, которые уже имели место быть и занимается исправлением уже допущенных ошибок $[8,11]$.

Третий пункт критики состоит в том, что как утверждает Галлиган, пересмотр имеет незакономерный, случайный характер, и что решения исправляются и что решения будут исправлены на разовой основе, в зависимости от ситуации [12]. B-четвертых, пересмотр критикуют за то, что процедура проводится медленно и дорого обходится. Этот пункт является одним из существенных оснований для рассмотрения альтернативных административных механизмов судебного решения, таких как система трибуналов по административным во- просам. Также судебный контроль отнимает много времени и представляется слишком непонятной для неспециалиста. Это очень существенный аргумент для слаборазвитых стран, где много бедных и неграмотных людей.

Примечательным в отношении приведенных пунктов критики является то, что, хотя они, несомненно, верны, но проблемы возникают только тогда, когда от судебного пересмотра требуется выполнение функции отличной от тех, для которых он был изначально создан. Как утверждает Вульф, судебный пересмотр действительно носит отрицательный и относящийся к прошлому характер, соответственно наряду с ним должны существовать другие положительные и прогрессивные средства развития основ управления [8]. В этом случае, судебный пересмотр остался бы исправительным средством судов и применялся бы только для устранения явных юридических ошибок. Например, Английское административное право становится все более и более заинтересованным в различных формах регулирования в профилактических целях, а не исключительно в исправительных методах контроля. Если судебный пересмотр требуется, чтобы выполнять функцию механизма внутренних проверок, он, естественно, может подвергаться критике за несоответствие данной задаче.

Из приведенного выше обсуждения ясно, что судебный пересмотр в его текущем состоянии представляется вовсе не подходящим для развития административного правосудия. Оно страдает от различных ограничений и неспособности в большинстве случаев исправить серьезные нарушения в действиях административных органов. С другой стороны, судебный пересмотр остается существенным элементом того, что должно стать интегрированной и сложной системой административного правосудия. Важный аргумент, выдвинутый в этой статье, касается не отмены судебного пересмотра или претензий к его эффективности и значимости, а скорее вопроса о том, что судебный пересмотр не может обеспечить все формы исправления положения в системе административного права, которое охватывает каждое направление деятельности исполнительной власти и почти каждый аспект жизни граждан. Если судебный пересмотр больше не является основным средством отправления правосудия, необходимо рассмотреть альтернативные формы судебного решения административных споров, таких как административные трибуналы. 
Административное и муниципальное право 8 (92) • 2015

\section{Библиография:}

1. Boulle, Harris \& Hoexter Constitutional and Administrative Law. 1989. C. 246-251.

2. President of the Republic of South Africa and Others v South African Rugby Football Union and Others.(SARFU 3). 2000. C. 148.

3. Pharmaceutical Manufacturers Association of South Africa and Another: In Ex Parte President of the Republic of South Africa and Others. 2000. C. 674.

4. Boulle Constitutional and Administrative Law. 1999. C. 256.

5. Milne AJ Estate Geekie Union Government. 1948. C. 502.

6. Hoexter Administrative Law. 2004. C. 104-105.

7. Milne J South African Roads Board v Johannesburg City Council. 1991. C. 13.

8. Woolf De Smith's Judicial Review. 2011. C. 3.

9. Fuller The Forms and Limits of Adjudication.1992. C. 353.

10. Hoexter Administrative Law. 2000. C. 18; Harlow \& Rawlings Law and Administration. 2011. C. 123.; Hutchinson The Rise and Ruse of Administrative Law and Scholarship. 1985. C. 293.

11. Cane Administrative Law. 2004. C. 378.

12. Galligan Judicial Review and the Textbook Writers. 2012. C. 257.

\section{References (transliterated):}

1. Boulle, Harris \& Hoexter Constitutional and Administrative Law. 1989. S. 246-251.

2. President of the Republic of South Africa and Others v South African Rugby Football Union and Others.(SARFU 3). 2000. S. 148.

3. Pharmaceutical Manufacturers Association of South Africa and Another: In Ex Parte President of the Republic of South Africa and Others. 2000. S. 674.

4. Boulle Constitutional and Administrative Law. 1999. S. 256.

5. Milne AJ Estate Geekie Union Government. 1948. S. 502.

6. Hoexter Administrative Law. 2004. S. 104-105.

7. $\quad$ Milne J South African Roads Board v Johannesburg City Council. 1991. S. 13.

8. Woolf De Smith's Judicial Review. 2011. S. 3.

9. Fuller The Forms and Limits of Adjudication.1992. S. 353.

10. Hoexter Administrative Law. 2000. S. 18; Harlow \& Rawlings Law and Administration. 2011. S. 123.; Hutchinson The Rise and Ruse of Administrative Law and Scholarship. 1985. S. 293.

11. Cane Administrative Law. 2004. S. 378.

12. Galligan Judicial Review and the Textbook Writers. 2012. S. 257. 